\title{
Performance-Associated Factors of Elderly Patients with a Low Education Level, with Acquired Language Alterations in Tests to Explore Executive Functions
}

\author{
Erislandy Omar-Martinez ${ }^{1}$, Mariana Pino-Melgarejo² ${ }^{2}$ Claudia Idárraga-Cabrera ${ }^{3}$, \\ Yisel Rodríguez-Aldana ${ }^{1}$ \\ ${ }^{1}$ Universidad de Oriente, Santiago de Cuba, Cuba \\ ${ }^{2}$ Universidad Autónoma del Caribe, Barranquilla, Colombia \\ ${ }^{3}$ Universidad de la Costa, Barranquilla, Colombia \\ Email: omar29681@gmail.com
}

How to cite this paper: Omar-Martinez, E., Pino-Melgarejo, M., Idárraga-Cabrera, C. and Rodríguez-Aldana, Y. (2017) Performance-Associated Factors of Elderly Patients with a Low Education Level, with Acquired Language Alterations in Tests to Explore Executive Functions. World Journal of Neuroscience, 7, 293-306.

https://doi.org/10.4236/wjns.2017.73025

Received: Novenber 28, 2016

Accepted: July 17, 2017

Published: July 20, 2017

Copyright $\odot 2017$ by authors and Scientific Research Publishing Inc. This work is licensed under the Creative Commons Attribution International License (CC BY 4.0).

http://creativecommons.org/licenses/by/4.0/

\begin{abstract}
Introduction. Secondary alterations of executive functions occur in brain injuries together with the primary neuropsychological symptoms, irrespective of the location of the damage and the affected neural networks. Such secondary alterations of executive functions in the presence of language alterations, which is the most frequent primary neuropsychological alteration, in addition to exacerbating the linguistic processing deficit, may be associated to multiple factors inherent to the brain injury or the injured patient. Purpose. To describe the secondary neuropsychological alterations of executive functions in elderly patients with low education levels with acquired language disorders and determine general factors of the injury and of the injured patient (etiology, location, time ot recovery from the injury, age, education level), associated to such secondary alterations of the Attentional Control System. Patients and Methods. The study was conducted on 68 elderly patients with a low education level with language acquired disorders, of both sexes, ranging between 60 and 80 years of age. The executive functions explored included cognitive flexibility, impulsivity control and inhibition of irrelevant automatisms, with the Trail Making Test, the Porteus Maze Test and series of loops. Statistical processing involved a Distribution of Frequencies and Multiple Ordinal Regression. Results and Conclusions. The statistical analysis found secondary neuropsychological alterations of the executive functioning in the elderly patients with language disorders of the study that are associated to the location and the time of recovery from the injury and are irrespective of age, education level and etiology of the injury.
\end{abstract}




\section{Keywords}

Impulsivity Control, Cognitive Flexibility, Executive Functions, Irrelevant Automatisms Inhibition, Acquired Language Disorders

\section{Introduction}

Multiple neuropsychological alterations of varying severity and depth occur in the presence of brain injury, which affect several processing subsystems of the cognitive system. Cognitive neuropsychology differentiates such alterations into primary and secondary alterations [1].

Primary alterations result from a direct damage to the processing components and mechanisms of the subsystem that exhibit the symptoms. In secondary neuropsychological alterations, the impairment exhibited by a processing subsystem is an indirect result, whether from the impairment of the damaged subsystem or from compensation mechanisms set in motion by the cognitive system in an attempt to reorganize cognitive function after the brain injury [2] [3] [4].

The secondary alterations that appear after a brain injury usually accompany the primary neuropsychological alterations and respond to the clinical and topographical nature of the primary injury [1]. However, apart from the topographical location of the primary damage and its clinical features, in every brain injury, together with the primary syndrome and concomitant with the abovementioned pattern of secondary alterations, a pattern of secondary alterations of executive functions is established [4] [5]. As it is, a fact that every brain injury results in secondary alterations that may involve the alert system, the orientation system toward environmental stimuli of the Attention System, and the components and mechanisms of executive functions [1] [6] [7].

This appearance of secondary alterations of the attentional mechanisms and executive functions that occurs in the presence of every brain injury, takes place because the destruction of cognitive automatisms occurring in brain injuries increases the demand for processing and executive control resources for implementing conducts that used to be performed automatically. This implies increased consumption of attentional resources to regulate behavior [1] [2] [3] [4] [6] and a reduction of the Cognitive System resource fund. In addition to aggravating the primary symptoms, this produces alteration of executive functions, which are responsible for controlling the Cognitive System resource fund.

According to Moscovitch [8], executive functions or, the attentional control system, as he calls them, assess the needs of the Cognitive System to establish the degree of priority of the information; summon the relevant information, assess the resources required by the working memory to maintain active the necessary representations and operations required during information processing, verify the degree of suitability of the cognitive goals to the demands of the environment, and control the allocation of resources: All of this is done by executive functions through their information selection and executive control mechanisms. 
The selection of information implies the selection, maintenance and disconnection of relevant information and inhibition of irrelevant automatisms. Both operations demand cognitive flexibility that allows alternating between more than two tasks. While executive control implies controlling impulsivity and controlling execution of the Cognitive System's plans and goals [1] [3] [4] [7].

Starting from these mechanisms of executive functions, cognitive neuropsychology suggests that their alterations are expressed as deficits, both to activate and disconnect information and maintain the cognitive flexibility required to alternate the attentional focus, as well as to inhibit automated routines that tend to prevail and respond in a planned, voluntary way to situations in the environment that demand immediate attention [1] [3] [4] [9]. The peculiarities of these alterations of executive functioning, when secondary, arise from the interaction between the primary syndrome and factors inherent to the brain lesion and the injured patient [1] [10].

In the case of acquired language alterations, secondary alterations of executive functions exhibit singular clinical characteristics due to the manner in which cognitive function is compromised. Acquired language alterations are usually a consequence of cerebrovascular accidents or traumatic brain injury, pathologies that damage broad brain areas [1] [11] [12] [13]. This affects several neural networks and establishes an important physiopathological process that implies the loss of multiple cognitive automatisms which implementation requires mental resources and conscious control, affecting executive function [1] [4] [14]. Alterations of executive functions in acquired language alterations worsen linguistic deficits and produce other secondary impairments [4].

The secondary alterations of executive functions exhibited by patients with acquired language alterations hinder the allocation of resources for linguistic processing and optimal distribution between verbal representations and operations active at each moment. This affects the selection of relevant verbal information and inhibition of the irrelevant, evaluation of the linguistic processing needs and allocation of the resources required to maintain the necessary linguistic representations and operations active in the verbal working memory [1] [3] [4] [5].

However, despite the implications of secondary alterations of executive functioning for patients with acquired language alterations, research on the matter is scarce. In fact, few studies address the alterations of the different executive functions in the presence of brain injury and their possible relation with general factors of the lesion and its consequences to the patients' Cognitive System functioning.

In the literature, studies of executive functions refer to their specific character in psychiatric or neurological illnesses [15] [16] [17]. In publications like "Revista de Neurología", studies of executive functions are linked to many other disorders [18]. However, in an exhaustive search in editions of such magazine in the last ten years, no referral is made to studies on executive functions of elderly patients with low education level with acquired language alterations. Only a few authors refer to general matters on the topic [3], without delving into the relation between the nature, severity and depth of the alteration of executive func- 
tions and the etiology of the lesion, time of recovery from the damage, extent and location, or patient age. All this, despite its relevance for designing and implementing diagnostic and rehabilitation strategies in each patient.

In this context, one could ask, what alterations of executive functions appear in elderly patients with a low education level with acquired language alterations? Is there a relation between general factors of the lesion and of the injured patient, and alterations of executive functions? What general factors of the lesion and of the injured patient are associated to alterations of executive functions in elderly patients with a low education level with acquired language alterations? This article attempts to answer these questions. It is written with the purpose of describing executive functions alterations (cognitive flexibility, impulsivity control and inhibition of irrelevant automatisms) exhibited by elderly patients with a low education level with acquired language alterations, and determining general factors of the brain lesion and of the injured patient (damage etiology, location of lesion, time of recovery from the damage, age and education level) associated with such executive functions alterations.

\section{Patients and Methods}

\subsection{Population of the Study}

A cross-sectional descriptive-correlational study was conducted from May through December 2015, in the Language Pathology consult of the "Centro de Estudios de Neurociencias y Procesamiento de Imágenes y Señales" of Universidad de Oriente. This study included in a consecutive way, the 68 elderly patients with acquired language alterations secondary to brain injury that fulfilled the following selection criteria: between 60 and 80 years old; intact motor function of upper limbs, visual-spatial coordination and sensory capacities; no history or clinical evidence of mental confusion, psychopathological disorders, mental deficit disorder or neurodegenerative symptoms; informed consent for taking part in the research.

\subsection{Methodology}

Each work session took place with the exclusive presence of the evaluator and the evaluated person, who was controlled for the possible presence of neuropharmaceuticals or other variables that could affect test performance.

Two hypotheses were assumed in the research: 1) "Elderly persons with acquired language alterations resulting from brain injury exhibit secondary alterations of cognitive flexibility, impulsivity control and inhibition of irrelevant automatisms, that reach different levels of severity and depth;" 2) "The secondary alterations of cognitive flexibility, impulsivity control and inhibition of irrelevant automatisms displayed by elderly persons with acquired language alterations resulting from brain injury are associated to the etiology of the lesion, the topographical location of the lesion, the time of recovery from the brain damage, age, and education level."

Verification of these hypotheses implied consideration of the variables: age 
(60 - 70 years, 71 - 80 years), education level (illiterate, taught to read and write, unconcluded primary, concluded primary, unconcluded secondary), etiology of the lesion (vascular, trauma, tumoral), topographical location of the lesion (anterior, posterior, anteroposterior), time of recovery from the damage (1 - 6 months, 7 - 12 months, 13 - 18 months), cognitive flexibility (adequate, deficit, disruption), impulsivity control (adequate, deficit, disruption) and inhibition of irrelevant automatisms (adequate, deficit, disruption).

The data to confirm the hypotheses were obtained with the following tests:

- Trail Making Test B. Explores cognitive flexibility. It consists in the graphical execution of a verbal series that alternates two automated series. The subject must alternate between consecutive numbers and letters, enclosed in circles and randomly distributed over a sheet of paper. Grades are reported as the number of seconds required to execute the task. It is graded based on age and education level, and taken to a scale of 0 - 4 points. 0 (more than 93 seconds): pathological performance, 1 (from 69 to 93 seconds): Border Line performance and 2 - 4 points (less than 68 seconds): normal performance [1] [19] [20] [21] [22].

- Porteus Maze Test. Explores impulsivity control. Consists in the execution of 10 mazes, where the first 7 have 2 solution opportunities and the last 3 have 4. A line must be traced from a starting point to an exit without lifting the pencil. Test scoring takes into account how participants coped with the Test. Failure in executing a maze implies failure in coping. Adequate coping of all mazes: regular performance. Failure in coping in one or two non-consecutive mazes: Border Line performance. Failure of coping in two consecutive or more than two non-consecutive mazes: pathological performance [1] [4] [20] [23].

- Series of Loops. Assess inhibition of irrelevant automatisms. Consists in the execution of a series of loops. Grading is done based on calculation of the test's Execution Index (IE), for which is considered the total of loops executed (be) and errors in execution (ee). $I E=100 \times(e e / b e)$. The value of $I E$ can range between 0 and 100. $I E$ between 0 - 16: regular performance. $I E$ between $17-25$ : Border Line performance. $I E>25$ : pathological performance [1] [4].

\subsection{Description of the Procedure}

Once the population of the study was selected and the necessary data obtained, the tests to explore executive functions were administered. This was followed by data analysis and statistical processing with computer program SPSS. First, Frequency Distribution was implemented to verify the first hypothesis; this was followed by implementation of Multiple Ordinal Regression, with 0.05 significance and a $95 \%$ confidence interval to verify the second hypothesis.

\section{Results}

$64.7 \%$ of the 68 patients that comprised the study population for this research were male and $35.3 \%$ were female. 
Average age was 72.3 years, with an age range from 60 to 80 years. Reported age for $41.2 \%$ of patients ranged between 60 and 69 years, while $58.8 \%$ reported ages between 70 and 80 years.

Education level for $20.6 \%$ of patients was unfinished secondary. $14.7 \%$ of the cases reported completed primary level, $38.2 \%$ reported uncompleted primary level, $14.7 \%$ reported having been taught to read and write and $11.8 \%$ reported being illiterate.

As to etiology of the brain lesion, in $61.8 \%$ of patients it was a vascular lesion (in $50.0 \%$ of subjects it was an ischemic vascular lesion and in $11.8 \%$ it was of the vascular hemorrhagic type). Trauma etiology was reported in $26.5 \%$ of total patients and $11.8 \%$ of the cases reported neoplastic etiology.

The topographic location of the brain lesion, in $52.9 \%$ of patients was located in the posterior cortex (occipito-parieto-temporal) of the left hemisphere. In $35.3 \%$ of patients, the lesion was located in the anterior cortex (frontal) of the left hemisphere. While in $11.8 \%$ of the cases, the lesion affected anterior and posterior cortical structures (frontal and temporoparietal essentially) of the left hemisphere. None of the cases reported right or bilateral location of the brain damage.

Time of recovery from the brain damage of total patient's ranges between 1 and 17 moths. The average time of recovery from the brain damage is 8.1 months, being higher in $50.0 \%$ of the study population; $35.3 \%$ of the patients recorded damage recovery periods between 1 and 6 months; 44.1\%, recorded recovery periods between 7 and 12 months, and 20.6\% recorded recovery periods between 13 and 18 months.

Cognitive flexibility was adequate in $14.7 \%$ of patients (regular performance in the Trail Making Test). 50.0\% of the cases recorded cognitive flexibility deficit (Border Line performance in the Trail Making Tests). While, the $35.3 \%$ of the cases, exhibited cognitive flexibility disruption (pathological performance in Task $B$ of the Trail Making Test).

Impulsivity control was adequate in $32.4 \%$ of patients (regular coping in the Porteus Maze Test). 32.4\% of the cases recorded impulsivity control deficit, (Border Line coping in the Porteus Maze Test). While, 35.3\% of the cases exhibited impulsivity control disruption (pathological coping in the Porteus Maze Test).

Inhibition of irrelevant automatisms was adequate in $35.3 \%$ of the patients (Regular Execution Index in the Series of Loops). 26.5\% of the cases recorded inhibition of irrelevant automatisms deficit (Border Line Execution Index in the Series of Loops). While $38.2 \%$ of the cases exhibited inhibition of irrelevant automatisms disruption (Pathological Execution Index in the Series of Loops).

As shown in Tables 1-3, the estimation of parameters in the Multiple Ordinal Regression implemented, with probabilities associated to the test $>0.05$ ( $p>$ $0.05)$, with a $95 \%$ confidence interval, enable us to assume that the factors: age, education level, and etiology of the lesion, are not associated to alterations in cognitive flexibility, control of impulsivity and inhibition of irrelevant automat- 
Table 1. Associated factors with cognitive flexibility.

\begin{tabular}{|c|c|c|c|c|}
\hline Factor & Estimation & IC $(95.0 \%)$ & Wald & $P$ \\
\hline Age & 1.842 & 6,$12 ;-2,43$ & 0.71 & 0.391 \\
\hline Grade level & 3.17 & $-2.94 ; 9.15$ & 1.01 & 0.314 \\
\hline Etiology of Brain Injury & 2.54 & $-4.91 ; 10.03$ & 0.44 & 0.504 \\
\hline Topographic localization of injury & -17.78 & $-11.90 ;-2.86$ & 35.19 & 0.001 \\
\hline Time of Recovery from the Brain Damage & 9.84 & $17.49 ; 2.18$ & 6.35 & 0.012 \\
\hline \multicolumn{5}{|c|}{ Adjustment to the model $=26.46$} \\
\hline
\end{tabular}

Table 2. Associated factors with impulsiveness control.

\begin{tabular}{ccccc}
\hline Factor & Estimation & IC (95.0\%) & Wald & $P$ \\
\hline Age & 1.58 & $-5.33 ; 8.55$ & 0.21 & 0.653 \\
Grade level & 5.38 & $-1.96 ; 12.74$ & 2.06 & 0.151 \\
Etiology of Brain Injury & 5.12 & $-1.42 ; 11.67$ & 2.35 & 0.125 \\
Topographic localization of injury & 22.41 & $40.13 ; 4.69$ & 6.14 & 0.013 \\
Time of Recovery from the Brain Damage & 18.77 & $5.93 ; 31.62$ & 8.20 & 0.004 \\
\multicolumn{4}{c}{ Adjustment to the model $=0.00$} \\
\end{tabular}

Table 3. Associated factors with inhibition of irrelevant automatisms.

\begin{tabular}{ccccc}
\hline Factor & Estimation & IC (95.0\%) & Wald & $P$ \\
\hline Age & 4.61 & $-15.26 ; 6.04$ & 0.72 & 0.396 \\
Grade level & 16.01 & $32.14 ; 0.12$ & 3.78 & 0.054 \\
Etiology of Brain Injury & 7.12 & $-14.92 ; 0.67$ & 3.21 & 0.073 \\
Topographic localization of injury & 27.91 & $-50.58 ;-5.23$ & 5.81 & 0.011 \\
Time of Recovery from the Brain Damage & 27.90 & $5.23 ; 50.58$ & 5.81 & 0.016 \\
\multicolumn{4}{c}{ Adjustment to the model $=0.00$} \\
\hline
\end{tabular}

isms exhibited by patients with acquired language alterations. While the probabilities associated to the test $<0.05(p<0.05)$, with a $95 \%$ confidence interval, allow us to assume that: location of the lesion and time of recovery from the brain damage, are associated to alterations in cognitive flexibility, control of impulsivity and inhibition of irrelevant automatisms exhibited by patients with acquired language alterations studied.

\section{Discussion}

As explained in the introduction of this article, suffering brain damage implies, in addition to generating a primary neuropsychological syndrome, the loss of numerous processing resources of the Cognitive Systems and destruction of a series of automatisms that are executed normally without consumption of cognitive resources. This results in that conducts that were automatically implemented, start demanding processing resources and attention control. All of this 
greatly reduces the limited resource fund of the Cognitive System [1] [3] [4].

This condition implies that in the presence of any brain lesion that does not affect the structures supporting executive functions, it is common, together with the primary neuropsychological syndrome, that a pattern of secondary attention alterations appears in the executive functions [4], which, according to Moscovitch neurocognitive proposal, are those responsible for distributing and controlling the processing resource funds of the Cognitive System [8].

As suggested by Moscovitch [8], executive functions are tasked (through their information and executive control functions) with the selection, maintenance and disconnection of irrelevant automatisms that attempt entering the system, the alternation of attention between different active goals, the control of impulsivity, and control of the Cognitive System's plans and goals execution [3] [4].

Based on this functioning of executive functions (included within their information selection and executive control functions), cognitive neuropsychology assumes that the most significant alterations of this attentional component are expressed in the capacity to activate relevant information and its disconnection when it stops being relevant; in maintaining the cognitive flexibility required to alternate the attention focus between two or more stimuli; in the inhibition of strongly automated routines that tend to prevail; and in the capacity for controlled, planned, voluntary response to stimuli or surrounding situations, that demand attention and automatic and impulsive reaction [4] [6] [7] [9].

The clinical characteristics exhibited by these forms of alteration of executive functions, when expressed as secondary to a primary neuropsychological syndrome, will arise from the dynamic interaction among the alterations of the primary syndrome themselves (which are in turn worsened by the secondary alterations of executive functions) and factors inherent to the brain lesion and the injured patient [1] [10].

Hence, as shown in the analysis of results, the severity and depth of executive functions alterations secondary to acquired language alterations, reflect a significant inter-individual variability, associated, as shown by the statistical findings of this research, to the time of recovery from the brain lesion and the topographical location of the lesion.

These secondary alterations of executive functions, as noted by Omar-Martinez [1], can be expressed as deficits (partial impairment of the functions) or as disconnections (loss of functions).

In the case of cognitive flexibility, performance of elderly adults with low education level with acquired language alterations in the Trail Making Test reveals frequent alterations, with varying severity and depth levels. This, assuming Omar-Martinez criteria [1], is expressed as cognitive flexibility deficit or as cognitive flexibility disconnection.

Cognitive flexibility deficit appears as a difficulty to displace the attention focus on information that is no longer relevant, towards the new relevant information. In this case, the subject slowly alternates the attention focus between its active goals, which it reaches with much difficulty, or is barely able to complete 
just one of them [4] [10]. As to cognitive flexibility disconnection, it implies a loss of the function and is expressed as an inability to displace the attention focus from one task to another, or of information no longer relevant, to the new relevant information. This results in a complete constraint to perform more than one task simultaneously, observing a rigid, stereotyped and determined conduct [2] [4].

Although in the studied patient population both forms of altered cognitive flexibility were recorded, there was marked presence of cognitive flexibility deficit. A large part of patients, even though they exhibited difficulty in executing the task and recording prolonged execution times, were able to complete the established goals. This indicates they were able to allocate sufficient processing resources to attain, although in a longer time, the goals established by the test. These difficulties are also linked to the unspecified slowness exhibited by patients with brain damage, which makes them demand more than subjects with an intact brain, to execute any type of task that implies cognitive effort [2] [4].

Patients that recorded cognitive flexibility disconnection, in addition to exhibiting rigid, determined behaviors, were unable to adequately complete the test task. In these patients, together with impairment of cognitive flexibility, were recorded damage recovery times under 6 months and anterior or anteroposterior location of the brain lesion.

Patient execution of the Porteus Maze Test reveals frequent alterations in terms of impulsivity control, with varying severity and depth levels, which assuming Omar-Martinez Criteria [1], are expressed as impulsivity control deficit or as impulsivity control disconnection.

Impulsivity control deficit implies that patients have difficult responding in a voluntary, control, planned way to stimuli or surrounding situations that require automatic and impulsive attention and reaction. These alterations are expressed whether due to failure during an assessment of the attention-demanding situation and determination of an adaptive response, or to difficulties in controlling automatic, impulsive attention during the time in which the situation is valued in order to voluntarily assume a certain determination [2] [4].

In impulsivity control disconnection, before stimuli or surrounding situations that demand attention and automatic reaction, an impulsive, involuntary, unplanned conduct [4] prevails. This happens because the patient fails in assessing the situation in terms of the planned, voluntary determination of a response and cannot control the trend of responding automatically to the attention demands of the stimulus at hand, without assessing the situation, or the real demands that it implies [1] [4].

Although both types of impulsivity control alteration were recorded for the patient population with acquired language alterations, the number of patients exhibiting impulsivity control deficit is much higher than the number of patients exhibiting impulsivity control disconnection.

The severity and depth of the impulsivity control alterations exhibited by the patients with acquired language alterations, as shown by the statistical findings, 
are associated to the time of recovery from the brain lesion and its topographical location.

Taking this into account, it was expected that a parietal location of the lesion implied an aggravation of the alterations for maze execution. The task of the test, in addition to recruiting structures in the prefrontal area of the brain, based on impulsivity control and strategic planning, demands visual-spatial functions that essentially recruit parietal structures [23]. However, no elements are recorded that indicate a worsening of the alterations in patients with parietal damage. Nevertheless, the time of recovery from the damage is also associated to the recorded alterations of executive functions, and definitely influences in patient's executions [24].

In the inhibition of irrelevant automatisms, execution exhibited by the patients in the Series of Loops, reveals frequent alterations with varying severity and depth levels, which assuming Omar-Martinez Criteria [1], are expressed as irrelevant automatisms inhibition deficit or as irrelevant automatisms inhibition disconnection.

The fundamental characteristic of irrelevant automatisms inhibition deficit is that the subject, in the presence of situations similar to those in which it acquired strongly automated routines (which tend to prevail), exhibits difficulty inhibiting them, barely attaining or with much difficulty, implementation of the relevant conduct [1] [4]. The subject is capable of inhibiting automatisms, but with much difficulty.

While in irrelevant automatisms inhibition disconnection, the subjects are unable to inhibit automated routines that tend to prevail during performance of a task [1] [4]. Hence, the routine prevails in performance of the task and precludes implementation of the relevant conduct.

Both ways of irrelevant automatisms inhibition alterations are present in the patient population. However, as with cognitive flexibility and impulsivity control, patients that exhibit irrelevant automatisms inhibition deficit prevail.

These patients exhibited difficulty in inhibiting the automated routine during task execution, but although it demanded much effort, they were able to adequately implement the relevant conduct. This type of situation, as has already been mentioned, is common in the neuropsychological patient where the brain damage causes global slowness of the cognitive function [2] [4].

In the cases where inhibition of irrelevant automatisms disconnection was registered, the exhibited performance was distinctly pathological, as none of the patients was able to attain the relevant conduct.

In all the cases, as shown in the analysis of results, the best executions were reported in patients with posterior location of the brain lesion. Those cases with anterior location of the lesion that exhibited scarce alterations in the inhibition of irrelevant automatisms, exhibit prolonged times of recovery from the brain damage. It is therefore assumed that this factor lessened the involvements implied for functioning of the executive functions, damage in the anterior region of the brain, due to the limitations this type of lesion imposes on the Cognitive 
System's resource fund [4].

Nevertheless, it is important to value that the reported frontal damages, in addition to having been registered around the Drill area and showing different levels of topographical extension, in none of the cases directly affected frontal structures that, as assumed by authors like Moscovitch and Umiltà [8], Duncan [25] and García-Molina, Tirapu-Ustárroz, Luna-Lario, Ibáñez, and Duque [26], are at the basis of the functioning of executive functions.

The proven fact, based on the statistical findings obtained by means of the Multiple Ordinal Regression implemented in the research, of the connection between the topographical location of the lesion and the time of recovery from the brain lesion, with secondary alterations of the patient's executive functions during performance of the administered neuropsychological tests, is entirely consistent with what has been presented thus far, as well as the fact that age, education level and etiology of the lesion are not associated to the exhibited patient executive functions alterations.

From a neuropathology perspective, a lesion's topographical location, in general, is a neurological factor that by its own essence is associated to a large part of the characteristics shown by the neuropsychological alterations exhibited by patients with brain damage. On this factor depends the neural networks affected by the lesion, which directly or indirectly determine the primary neuropsychological alterations, as well as the areas to be affected due to the effect of diaschisis, which give rise overall, to the secondary neuropsychological alterations [27] [28].

The functional organization of the brain implies that specific brain areas are going to be recruited in a more or less defined way for the implementation of specific psychological functions. The cortical regions of both brain hemispheres, which are essentially responsible for cognitive function, are divided structurally and functionally, by the Central sulcus. From this, afferent processing of information takes place in the posterior regions of the cortex and efferent processing and mental control of activity (including executive functions) takes place in the anterior regions. This causes that secondary alteration that will be manifest in the functioning of executive functions in presence of a focal lesion, will be mediated by the anterior or posterior location of the lesion (in addition to being associated to the alterations inherent to the primary syndrome.) General physiopathology of the damage and the amount of processing resources and cognitive automatisms lost will depend on the location [2].

In frontal lesions, secondary affectation of executive functions function must be, therefore, more distinct and exhibit greater severity and depth than in parieto-temporo-occipital lesions. This because cognitive functions supported by frontal brain circuits make the greatest demand for processing resources from the Cognitive System [2] [4].

The time of recovery from the brain damage, defined as the period elapsed since the patient sustained the lesion until the time he is subject to the neuropsychological assessment [1], is a very important factor associated, as shown by 
the statistical data obtained, to the secondary alterations of the executive functions registered in patients with acquired language alterations, based on their performance in the neuropsychological tests administered. This factor has a significant influence in the severity and depth of attentional alterations, mainly when they are a consequence of a general reduction in resources of the Cognitive System.

Hence, recovery from the physiopathological conditions caused by brain injury and the brain's capacity to modify functions and compensate damages has proven to play an important role in the recovery of cognitive functions and processing resources after brain damage [29]. This indicates that the time of recovery from the damage is linked to neuroplastic changes subsequent to lesion acquisition. Because the greater of time elapsed after the lesion is sustained, the less severe and deep are the executive functions deficits.

The brain plasticity at the core of matters linked to the time of recovery from brain damage expresses the nervous system's adaptive capacity to minimize the effects of lesions through a structural and functional reorganization of the brain [30]. Important changes occur in brain physiology after a brain injury, which recovers from the global effects of the lesion, and secondary symptoms associated to the primary symptoms start alleviating. This progressive recovery of functions will depend of factors such as the brain region compromised, etiology of the lesion and the age at which patient sustained the damage (the brain's capacity to adapt to a lesion and to compensate the lesion's effects is greater in an immature brain than in an adult brain) [31] [32] [33].

This factor is significantly associated to how the patient will perform in the different neuropsychological tests it will be subject to, as well as its adaptation to its disability and compensation of its deficits. These peculiarities that have been argued are reflected in the results obtained in this research, where the most compromised executions of the different functioning of executive functions are encountered in patients with the shortest recovery time from the brain injury.

\section{References}

[1] Omar-Martinez, E. (2012) Factores asociados a alteraciones secundarias del Sistema de Control Atencional en pacientes afásicos. Revista Neurología Argentina, 4, 5966. https://doi.org/10.1016/j.neuarg.2011.12.001

[2] Benedet, M.J. (2003) Metodología de la investigación básica en neuropsicología cognitiva. Revista de Neurología, 36, 45-66.

[3] Benedet, M.J. (2006) Acercamiento neurolingüístico a las alteraciones del lenguaje. Neurolingüística. Aplicaciones a la clínica. EOS, Madrid.

[4] Benedet, M.J. (2012) Fundamento teórico y metodológico de la neuropsicología cognitiva. IMSERSO, Madrid.

[5] Omar-Martinez, E. (2011) Factores que determinan el rendimiento de pacientes afásicos en pruebas para la exploración de funciones del Sistema de Control Atencional. Universidad de la Habana, La Habana.

[6] Luck, E.J., Woodman, G.F. and Vogel, E.K. (2000) Event-Related Potential Studies of Attention. Trends in Cognitive Sciences, 4, 432-440.

https://doi.org/10.1016/S1364-6613(00)01545-X 
[7] Yantis, S. and Serencesy, J.T. (2003) Cortical Mechanisms of Space-Based and Object-Based Attentional Control. Current Opinion in Neurobiology, 13, 187-193. https://doi.org/10.1016/S0959-4388(03)00033-3

[8] Moscovitch, M. and Umilta, C. (1991) Modularity and Neuropsychology: Modules and Central Processes in Attention and Memory. Behavioral and Brain Sciences, 19, 1-59.

[9] Kenemans, J.L., Bekker, E.M., Lijffijt, M., Overtoom, C.E., Jonkman, L.M. and Verbaten, M.N. (2005) Attention Deficit and Impulsivity: Selecting, Shifting, and Stopping. International Journal of Psychophysiology, 58, 59-70. https://doi.org/10.1016/j.ijpsycho.2005.03.009

[10] García-Ogueta, M.I. (2001) Mecanismos atencionales y síndromes neuropsicológicos. Revista de Neurología, 32, 463-467.

[11] Ardila, A. (2014) Aphasia Handbook. Florida International University, Miami.

[12] Bembibre, R., Soto, A., Díaz, D. and Hernández, A. (2001) Epidemiología de la Enfermedad Cerebrovascular Hemorrágica en la Región Central de Cuba. Revista de Neurología, 33, 601-604.

[13] Berthier, M.L. (2005) Poststroke Aphasia: Epidemiology, Pathophysiology and Treatment. Drug and Aging, 22, 163-182. https://doi.org/10.2165/00002512-200522020-00006

[14] Perrone, M., Fodaro, K., Perini, C. and Pietrapiana, P. (2005) Aspectos Clínicos del Paciente con daño Cerebral Después de un año de Tratamiento. Revista Española de Neuropsicología, 7, 3-15.

[15] Fuentes, L.J. (2001) Déficit de Atención Selectiva en la Esquizofrenia. Revista de Neurología, 32, 387-391.

[16] Martos-Pérez, J. (2008) Procesos de Atención en el Autismo. Revista de Neurología, 46, 69-70.

[17] Vázquez-Marrufo, M., González-Rosa, J., Vaquero-Casares, E., Duque, P., Borges, M. and Izquierdo, G. (2009) Déficit Atencional en Pacientes con Esclerosis Múltiple. Revista de Neurología, 48, 453-458.

[18] Rodríguez-Jiménez, R., Cubillo, A., Jiménez-Arriero, M.A., Ponce, G., Aragüés-Figuero, M. and Palomo, T. (2006) Disfunciones Ejecutivas en Adultos con Trastorno por Déficit de Atención e Hiperactividad. Revista de Neurología, 43, 678-684.

[19] Giovagnoli, A.R., Del-Pesce, M., Mascheroni, S., Simoncelli, M. and Laiacona, M. (1996) Trail Making Test: Normative Values from 287 Normal Adult Controls. Italian Journal of Neurological Science, 17, 305-309. https://doi.org/10.1007/BF01997792

[20] Lezak, M. (1995) Neuropsychological Assessment. Oxford University Press, New York.

[21] Ruffollo, L.F., Guilmette, T.J. and Willis, G. (2010) Comparison of Time and Error Rates on the Trail Making Test among Patients with Head Injuries, Experimental Malingerers, Patients with Suspect Effort on Testing and Normal Controls. The Clinical Neuropsychologist, 14, 223-230. https://doi.org/10.1076/1385-4046(200005)14:2;1-Z;FT223

[22] Stuss, D.T., Bisschop, S.M., Alexander, M.P., Levine, B., Katz, D. and Izukawa, D. (2011) The Trail Making Test: A Study in Focal Lesion Patients. Psychological Assessment, 13, 230-239. https://doi.org/10.1037/1040-3590.13.2.230

[23] Marino, J.C., Fernandez, A.L. and Alderete, A.M. (2011) Valores Normativos y Validez Conceptual del Test de Laberintos de Porteus, en una Muestra de Adultos Argentinos. Revista Neurológica Argentina, 26, 102-107. 
[24] Iglesias-Sarmiento, V. (2008) Lesiones Cerebrales y Procesos Cognitivos. Universidad de Vigo, Vigo.

[25] Duncan, J. (1995) Attention, Intelligence, and the Frontal Lobes. In: Gazzaniga, M.S., Ed., The New Cognitive Neurosciences, MIT Press, Cambridge, 721-733.

[26] García-Molina, A., Tirapu-Ustárroz, J., Luna-Lario, P., Ibáñez, J. and Duque, P. (2010) Son lo Mismo Inteligencia y Funciones Ejecutivas? Revista de Neurología, 50, 738-746.

[27] Anderson, S.W., Damasio, H. and Tranel, D. (1990) Neuropsychological Impairments with Lesions Caused by Tumor or Stroke. Archives of Neurology, 47, 397 405. https://doi.org/10.1001/archneur.1990.00530040039017

[28] Narbona, J. and Crespo-Eguílaz, N. (2005) Trastornos de Memoria y de Atención en Disfunciones Cerebrales del Niño. Revista de Neurología, 40, 33-50.

[29] Ríos-Lago, M., Muñoz-Céspedes, J.M. and Paúl-Lapedriza, N. (2007) Alteraciones de la Atención tras Daño Cerebral Traumático: Evaluación y Rehabilitación. Revista de Neurología, 44, 291-297.

[30] Bergado, J.A. and Almaguer, W. (2000) Mecanismos Celulares de la Neuroplasticidad. Revista de Neurología, 31, 1070-1095.

[31] Aguilar, F. (2013) Mecanismos Biológicos de la Plasticidad Neuronal. Plasticidad y Restauración Neurológica, 2, 143-152.

[32] Elbert, T. and Rockstroh, B. (2006) Reorganization of Human Brain Cortex: The Range of Changes Following Use and Injury. Neuroscientist, 14, 129-141.

[33] Sans, A., Colomé, R., López-Sala, A. and Boix, C. (2009) Aspectos Neuropsicológicos del Daño Cerebral Difuso Adquirido en la Edad Pediátrica. Revista de Neurología, 48, 23-26.

\section{Submit or recommend next manuscript to SCIRP and we will provide best} service for you:

Accepting pre-submission inquiries through Email, Facebook, LinkedIn, Twitter, etc. A wide selection of journals (inclusive of 9 subjects, more than 200 journals)

Providing 24-hour high-quality service

User-friendly online submission system

Fair and swift peer-review system

Efficient typesetting and proofreading procedure

Display of the result of downloads and visits, as well as the number of cited articles

Maximum dissemination of your research work

Submit your manuscript at: http://papersubmission.scirp.org/

Or contact wjns@scirp.org 